\title{
Development, content validity and cross-cultural adaptation of a Patient-Reported Outcome Measure for Real-time Symptom Assessment in Irritable Bowel Syndrome
}

\section{Running title: Development of momentary PROM for IBS}

L. Vork ${ }^{1}$, D. Keszthelyi ${ }^{1}$, Z. Mujagic ${ }^{1}$, J.W. Kruimel ${ }^{1}$, C. Leue ${ }^{2}$, I. Pontén ${ }^{3}$, H. Törnblom ${ }^{3}$, M. Simrén ${ }^{3,9}$, A. Albu-Soda ${ }^{4}$, Q. Aziz ${ }^{4}$, M. Corsetti ${ }^{5,6}$, L. Holvoet ${ }^{5}$, J. Tack ${ }^{5}$, S.S. Rao ${ }^{7}$, J. van Os ${ }^{2}$, E.G. Quetglas ${ }^{8}$, D.A. Drossman ${ }^{9}$, A.A.M. Masclee $^{1}$

${ }^{1}$ Division of Gastroenterology-Hepatology, Department of Internal Medicine, NUTRIM School of Nutrition and Translational Research in Metabolism, Maastricht University Medical Center+, Maastricht, The Netherlands.

${ }^{2}$ Department of Psychiatry and Medical Psychology, Maastricht University Medical Center+, Maastricht, The Netherlands.

3 Department of Internal Medicine, Institute of Medicine, Sahlgrenska Academy, University of Gothenburg, Gothenburg, Sweden.

\footnotetext{
${ }^{4}$ Wingate Institute of Neurogastroenterology, Centre for Neuroscience and Trauma, Blizard Institute, Barts and the London School of Medicine \& Dentistry, Queen Mary University of London, London, United Kingdom.

5 Translational Research Center for Gastrointestinal Disorders (TARGID), Department of Clinical and Experimental Medicine, University of Leuven, Leuven, Belgium.

${ }^{6}$ Nottingham Digestive Diseases Biomedical Research Unit, National Institute for Health Research, Nottingham University Hospitals NHS Trust, University of Nottingham, Nottingham, UK.

${ }^{7}$ Digestive Health Center, Medical College of Georgia, Georgia Regents University, Augusta, Georgia, USA.

${ }^{8}$ Medical Intelligence, Early Clinical Development, Grünenthal GmBH, Aachen, Germany.

${ }^{9}$ Center for Functional Gastrointestinal and Motility Disorders, University of North Carolina at Chapel Hill, Chapel Hill, NC, USA.
}

\section{Corresponding author:}

Name: Lisa Vork

Postal address: $\quad$ P.O. Box 5800

6202 AZ Maastricht, The Netherlands

Email address: L.vork@maastrichtuniversity.nl

Telephone number: +31 (0) 433881982

Fax number: $\quad$ +31(0) 433875006 


\section{ABSTRACT}

BACKGROUND End-of-day questionnaires, which are considered the gold standard for assessing abdominal pain and other gastrointestinal (GI) symptoms in irritable bowel syndrome (IBS), are influenced by recall and ecological bias. The Experience Sampling Method (ESM) is characterized by random and repeated assessments in the natural state and environment of a subject, and herewith overcomes these limitations. This report describes the development of a patient-reported outcome measure (PROM) based on the ESM-principle, taking into account content validity and cross-cultural adaptation.

METHODS Focus group interviews with IBS patients and expert meetings with international experts in the fields of neurogastroenterology \& motility and pain were performed in order to select the items for the PROM. Forward-and-back translation and cognitive interviews were performed to adapt the instrument for the use in different countries and to assure on patients' understanding with the final items.

KEY RESULTS Focus group interviews revealed 42 items, categorized into five domains: physical status, defecation, mood and psychological factors, context and environment, and nutrition and drug use. Experts reduced the number of items to 32 and cognitive interviewing after translation resulted in a few slight adjustments regarding linguistic issues, but not regarding content of the items.

CONCLUSIONS AND INFERENCES An ESM-based PROM, suitable for momentary assessment of IBS symptom patterns was developed, taking into account content validity as well as cross-cultural adaptation. This PROM will be implemented in a specifically designed smartphone application and further validation in a multicenter setting will follow.

KEYWORDS: Irritable bowel syndrome, abdominal pain, GI symptoms, experience sampling method, momentary symptom assessment.

\section{KEY POINTS:}

- Retrospective patient reports of irritable bowel syndrome symptoms are influenced by recall and ecological bias.

- A digital patient-reported outcome measure (PROM) for momentary symptom assessment in irritable bowel syndrome, based on the experience sampling methodology, was developed, taking into account content validity and cross-cultural adaptation. 
- The developed ESM-PROM assesses real-time symptoms and influencing factors in daily life, and therefore has the potential to provide insight into the fluctuating IBS symptom pattern during the day and to identify individual symptom triggers. 


\section{INTRODUCTION}

Irritable bowel syndrome (IBS) is a functional gastrointestinal (GI) disorder, characterized by recurrent abdominal pain and altered bowel habits. It affects up to $20 \%$ of the Western population, with a female predominance.(1-4) IBS leads to a reduction of quality of life, increased utilization of health care and higher (in)direct costs for society. $(5,6)$ Since specific biological markers are currently unavailable, IBS is a symptom-based diagnosis (7-10) and reliable symptom assessment methods are essential to investigate natural disease course and evaluate response to therapy.

Both the United States Food and Drug Administration (FDA) and the European Medicines Agency (EMA) recommend the use of a composite primary endpoint for clinical trials, in which abdominal pain as well as stool consistency/frequency is addressed. With regard to abdominal pain, a seven-day mean score on an 11-point Numeric Rating Scale (NRS) assessed at the end of each day is recommended. However, both guidelines address the challenge of capturing all clinically important symptoms associated with IBS in a reliable measure of treatment benefit, since IBS is a heterogeneous disorder with diverse and fluctuating symptom patterns. Therefore, the development of a multi-item patient-reported outcome (PRO) instrument, that captures all clinically important symptoms of the IBS population, is recommended.(11, 12) Furthermore, currently recommended retrospective (i.e. end-of-day), self-reported outcomes have important limitations. First, there is a high risk for recall bias, since retrospective information consists of a reconstruction of a few specific moments rather than a reliable reflection of symptoms over a predefined period of time.(13-15) Second, it is well described that memory retrieval is influenced by the individual's environment and mental state at the time of recall, known as ecological bias.(13,14) In conclusion, retrospectively reported patient experiences about symptoms in the past can be significantly distorted.

The Experience Sampling Method (ESM), also referred to as Ecological Momentary Assessment (EMA), may overcome these limitations. ESM is an electronic questioning method characterized by random, repeated assessments in the subject's current state and environment for several consecutive days. $(13,14,16)$ Hereby, ESM offers the opportunity to reduce the risk for recall and ecological bias and to capture symptom variability over time, while taking into account contextual, social and psychological factors, which might have an impact on IBS symptom reporting. ESM has been applied in a range of disorders, i.e. chronic pain, chronic fatigue and psychiatric disorders,(17-19) but has not been validated as a symptom assessment method for IBS. Only one study has been published reporting the use of ESM in an IBS population. Weinland et al. demonstrated that higher abdominal pain scores were reported in end-of-day diaries compared to ESM in IBS patients.(20) Additionally, our previously performed pilot trial on the correlation of Experience Sampling Method with currently 
used retrospective patient-reported outcomes supported our hypothesis that ESM provides more accurate information about IBS symptoms.(21)

The current report describes the development of a patient-reported outcome measure (PROM) for real-time measurement of abdominal and extra-abdominal symptoms, and their potential triggers, in IBS, using the ESM principle. In agreement with FDA guidelines on PROM development patient as well as expert input obtained by structured focus group interviews and expert meetings were used in the item selection process, herewith addressing content validity. Furthermore, cross-cultural adaptation was taken into account by performing cognitive interviews after forward-and-back translation of the developed instrument.(22)

\section{MATERIALS \& METHODS}

\section{Study Design}

The development of a novel PROM for symptom assessment in IBS, using the ESM principle, was performed in four phases: I) initial item selection, II) focus group interviews to obtain patients' input, III) expert meetings to obtain the input of international experts in the fields of neurogastroenterology and motility and pain, and IV) translations and cognitive interviews to assure on patients' understanding with the developed tool (cross-cultural adaptation). Throughout this report, the developed instrument will be referred to as 'ESM-PROM'.

\section{Phase I: Item selection}

In our previous pilot study, real-time ESM was compared to retrospective paper symptom assessments in IBS patients.(21) The IBS-specific ESM items used in this study were based on a developed framework of theoretical constructs for symptom assessment in an IBS population. These IBS constructs were obtained from currently used retrospective symptom surveys and qualitative studies, selected after an extended literature search.(23-29) The ESMspecific constructs, i.e. items regarding psychological status, social factors and context and environment at the moment of assessment, were derived from ESM questionnaires as used in previous studies at the department of Psychiatry of Maastricht University Medical Center + (Maastricht UMC+).(30, 31) Additionally, subjects, participating in the pilot study, gave their feedback about the feasibility and burden of ESM as an assessment tool and about the relevance of the items on the initial draft instrument (developed after first item selection). This feedback was taken into account for further selection. 


\section{Phase II: Focus group interviews}

\section{Recruitment of focus group participants}

Subjects between the age of 18 and 75 years and diagnosed with IBS, according to the Rome III criteria (7-9), were recruited via the outpatient department of the Gastroenterology and Hepatology division of Maastricht UMC+ as well as general practitioner practices in SouthLimburg, the Netherlands. All subjects were previously included in the Maastricht IBS Cohort.(32, 33) Subjects with organic diseases possibly explaining the gastrointestinal symptoms, as diagnosed by a physician, were not eligible for inclusion. Furthermore, subjects with prior abdominal surgery (except appendectomy, laparoscopic cholecystectomy and hysterectomy) were not included. Participants needed to be able to understand written Dutch and speak the Dutch language, since focus groups were conducted in Dutch. All subjects gave written informed consent prior to participation.

\section{Conducting and moderating focus group interviews}

Focus group meetings were arranged in order to select a relevant set of items for real-time symptom assessment in IBS using ESM, according to patient opinions. Subjects eligible for participation were invited to Maastricht UMC+ to participate in a focus group interview. Meetings took 90 minutes and were planned one by one, each preferably including six to eight participants, continuing until saturation of input was reached. Saturation was determined as meetings no longer augmenting any new items or information in addition to previous meetings. $(22,34)$ Focus groups were guided by a moderator (LV) and at least one assistantmoderator (ZM or DK) and were performed according to a predefined, two-stage framework, based on guidelines described in literature.(34-36) The first stage consisted of an open discussion, in which participants were instructed to bring forward every item they considered to be essential in an IBS symptom assessment tool aiming to get insight in their symptom pattern during daily life. This concept, rather than introducing specific items, was chosen to prevent bias to arise. During the second stage, participants were requested to criticize the ESM items, that were initially selected during phase I. We specifically asked them to argument which questions were relevant in a real-time symptom assessment method for IBS and which could be omitted to their opinion. Also, they were asked to define any incomprehensible items and to give their opinion about the most appropriate response scales.

\section{Analysis of focus group data}

Focus group discussions were recorded by video camera and additionally, attending investigators made notes. Video recordings were transcribed verbatim after the meetings and subsequently summarized in a spreadsheet database. In this, also the notes of the investigators and feedback of subjects in our previous pilot trial were added. Subsequently, 
this spreadsheet was used to evaluate whether to preserve, modify, delete or add items from the questionnaire to develop a draft instrument. Results from all focus group meetings were combined in the spreadsheet and are presented together as the results of phase II in this report.

\section{Phase III: Expert meeting}

Investigators with extensive experience in the fields of neurogastroenterology and motility and pain were gathered to obtain expert opinions regarding the further development of the ESMPROM. The international experts were invited for a face-to-face meeting and were asked to discuss all items that were selected during initial item selection (phase I) and the focus group meetings (phase II). They specifically criticized the items on relevance in clinical practice (i.e. does an item add something to the insight in a patient's symptom pattern and disease severity?) and suitability for a real-time symptom assessment method (i.e. will repeated, momentary assessment of this item result in measuring variability during the day?). On the basis of this discussion, a final set of questions was selected. The authors LV, DK, JK, CL, $\mathrm{QA}, \mathrm{MC}, \mathrm{EQ}$ and $\mathrm{AM}$ were present at the meeting and $\mathrm{MS}$ and $\mathrm{DD}$ gave their input via telephone conference.

\section{Phase IV: Translations and cognitive interviews}

In order to perform a further validation study in a multicenter, international context the ESMPROM, originally developed in Dutch, was translated into English and Swedish. Translation was performed using forward-and-back procedures, as described by the World Health Organization (WHO).(37) Additional individual cognitive interviews with native-speaking IBS patients were arranged with regard to each language (i.e. Maastricht $\mathrm{UMC}+$ regarding Dutch, Queen Mary University of London regarding English and University of Gothenburg regarding Swedish) to verify patient understanding with the developed items in each language. Participants were instructed to read out loud all items and response scales and to communicate items or answers they did not understand. Furthermore, they were asked to identify any revisions that could make the instrument more appropriate. All cognitive interviews were transcribed independently and decisions about revisions were made separately for each language.

Interviews were planned one by one continuing until saturation of input was reached. Inclusionand exclusion criteria for participants in this phase of the project were similar to those described under 'Phase II: Focus group interviews'. 


\section{RESULTS}

\section{Study population}

Patient characteristics of all subjects that participated in the different phases of the project are summarized in Table 1. With regard to the focus group interviews a total of 67 patients diagnosed with IBS according to the Rome III criteria (7-9) were invited to one of the focus group sessions. Thirty-two of them agreed to participate, however, only seventeen subjects were in fact present during four different meetings. Reasons for cancelation were illness $(n=6)$ and family circumstances $(n=1)$. Two subjects did not inform us about their reason for cancelation and another six did not cancel at all.

To take into account possible selection bias, demographical characteristics and symptom severity scores of the 17 focus group participants were compared to those of subjects, included in the Maastricht IBS cohort, that did not participate in the focus group meetings. Focus group participants were slightly older (median age 58.0 vs. 45.0 years, $p<0.05$ ), but no further clinical differences were found. Results are shown in Table $\mathrm{S} 1$.

\section{Phase I: Item selection}

The initially developed ESM instrument contained 60 items, based on five domains: physical status, defecation, mood, environmental \& social context, and drug use.

The twenty-six participants that completed ESM assessments during our previous pilot study were asked to evaluate practical issues of ESM as well as the relevance of all specific items on the instrument. With regard to practical aspects, a subset of the participants stated that the number (i.e. ten) of assessments during the day $(n=14 ; 53.8 \%)$ and the time (i.e. \pm 5 minutes) spent completing each assessment $(n=10 ; 38.5 \%)$ were quite burdensome. Furthermore, a few questions (mostly questions about psychological status, such as 'I feel enthusiastic' and 'I feel strong') were considered difficult to define, making these questions inappropriate for a PROM. In general, participants stated that questions about nutrition and relation between food and GI complaints should be included. The set of items constructed during phase I is shown in Table S2.

\section{Phase II: Focus group interviews}

Focus group interviews resulted in a reduction of the number of items from 60 on the initial draft instrument to 42 , with some slight modifications to the five domains: physical status, defecation, mood and psychological factors, context and environment, nutrition and drug use (Figure 1). The suggested modifications regarding each domain are summarized below. The resulting set of items is shown in Table S3. 


\section{Physical status}

Participants emphasized that abdominal pain is one of the most important symptoms to assess and they agreed on two essential elements in a real-time symptom assessment method; location and character of the pain. For pain location, all subjects supported the concept of a schematic picture of the abdomen in which they can indicate a particular abdominal region. One participant noted that it might be confusing which side of the picture reflects the left versus the right side of the abdomen, so it is important to clearly point this out within the picture (Figure 2). Furthermore, it was stated that it should be possible to indicate more than one abdominal region at a time. For assessment of the character of the pain participants suggested to insert several categories of which patients can choose one or more suitable categories for their pain at that moment. Suggested categories were cramp-like, sharp, stabbing, dull and bruise-like. Moreover, subjects agreed that it is important to assess whether the abdominal pain is continuous and prolonged or acute and short lasting.

In addition to abdominal pain, subjects agreed on the importance of scoring and reporting other GI symptoms associated with IBS: bloating, visible abdominal distension, abdominal rumbling, flatulence, belching, nausea and heartburn. Further, non-abdominal complaints as stated in the draft instrument (i.e. dizziness, palpitations, shortness of breath and sweating) were considered relevant for the majority of participants.

Lastly, fatigue, general illness (i.e. chill, the flu, fever) and comorbid symptoms were mentioned as possible factors provoking IBS symptoms. Regarding questioning methods, participants suggested solely asking after these conditions without suggesting any association with IBS symptoms, i.e. 'Do you feel tired?' instead of 'Do you think fatigue is influencing your IBS symptoms at this moment?' Since comorbid symptoms can be very widespread, a momentary question could be 'Do you have complaints of comorbid symptoms right now?', with answers on a Likert scale.

\section{Defecation}

Assessment of several aspects of bowel habits was considered essential since irregular bowel patterns can be one of the main symptoms itself as well as be associated with and influence abdominal symptoms. Regarding defecation, the participants came up with at least three essential elements: frequency, stool form and urgency. Frequency can be assessed asking 'how many times did you defecate since the previous assessment?' and answering using categories, i.e. 0 times, 1 time, etcetera. Participants concluded that stool form is properly assessed using the Bristol Stool Form Scale (BSFS) for each time of defecation, which they are familiar with due to existing symptom surveys they have completed before. Other items that were raised as potentially of relevance, but not essential, are painful and 
difficult defecation, whether or not being able to postpone defecation in case of urgency and bloody or mucinous stool.

The items about defecation on the initial draft instrument were considered relevant, but were lacking the possibility to report the frequency of defecation since the previous assessment. Therefore, subjects suggested asking after defecation frequency and subsequently consistency according to the BSFS (for each reported defecation). Furthermore, nearly all subjects agreed on the relevance of adding an item regarding the degree of fecal urgency and about whether the abdominal complaints did diminish after defecation. A few aspects of defecation were proposed by small subsets of participants, i.e. bloody stool $(n=1)$, mucus in stool $(n=2)$, painful defecation $(n=3)$ and whether patients were able to postpone a bowel movement $(n=3)$.

The last comment with regard to defecation was that in some cases having a bowel movement relieves the abdominal symptoms. Therefore, participants suggested adding a question asking 'Did having a bowel movement relieve your abdominal complaints?'

\section{Mood and psychological factors}

All participants agreed on the importance of assessing psychological factors given the oftenexperienced association between for instance negative emotions, fear for developing abdominal complaints or stress in general and IBS symptomatology. Furthermore, given the possibility that ESM offers to simultaneously assess for social, environmental and psychological features at the moment of symptom reporting (i.e. to overcome ecological bias as well as to evaluate for factors of influence on IBS symptoms), it is essential to include psychological items in the instrument. In total, ten items regarding a person's current mood or mental status were selected from the initial draft instrument. Additionally, an eleventh item, 'I feel good right now', was considered relevant.

\section{Context and environment}

Participants stated that the presence or experienced severity of IBS symptoms at a certain moment can depend on the concerning situation and therefore, as psychological factors, also contextual and environmental factors at the moment of assessment were considered relevant. Items 'Where am I?', 'Who is with me?' and 'What am I doing?' were therefore kept in the instrument (including the answer options). Additionally, all four focus group meetings resulted in adding one extra question in this section: 'My symptoms are limiting my current activities.' In total, based on input from the participants, this section is left with ten relevant items. 


\section{Nutrition and drug use}

Participants stressed that diet should be taken into account when assessing IBS symptoms and associated factors. Two components of nutrition were found to be essential, namely specific food items that may provoke symptoms and regularity in dietary pattern. Subjects suggested to insert a question about what someone ate, i.e. 'What did you eat since the last beep?', with categorical answers, in which more than one answer is possible at a time. Categories could be: carbohydrates, dairy products, spicy foods, fatty foods, onions/leek, cabbage, fruits, sweets, carbonated beverages and nuts. The participants were not able to suggest the best way to assess the regularity of the dietary pattern. Some suggested to insert a question asking 'How much did you eat since the last beep signal?' with answers on a Likert scale, in which the mean score is a normal amount of food for that particular person. Therewith, patients can score whether they ate less or more than what is usual for them.

With regard to drug use several important factors were determined: coffee, tea, alcohol, nicotine and medication use. Obviously, regular medication use should not be included in the momentary assessments, but subjects stated that it is important to ask whether patients used any occasional drugs. Answers could be categorical, i.e. painkillers, antacids, spasmolytics/antispasmodics, laxatives and antidiarrheals.

\section{Practical issues}

Lastly, we asked participants to discuss some practical issues concerning ESM. Most frequently discussed were the number of assessments per day and the acceptable time spent completing the assessments. Some subjects stated that 10 times a day, with 3 to 5 minutes per assessment would be acceptable. However, frequently, participants stated that this would not be possible for them due to their occupational situation. Some stated that 6 times a day during 5 minutes might be possible, but that there should be a longer period of time in which a person can respond after the beep signal. For example, it would be advisable to have the questions accessible for one hour after the signal, rather than only for 10 minutes.

Furthermore, the possibility of standard personalized answers was discussed. Participants raised the option of keeping former answers to the next assessment moment, so that questions have to be completed only in case of changes since the previous assessment. This might decrease the time needed for each participant.

\section{Phase III: Expert meeting}

All 42 items resulting from the previous phases of the project were discussed with regard to relevance in a momentary assessment method. It is important to emphasize that the developed 
ESM-PROM concerns not only real-time assessments of IBS symptomatology, but additionally takes into account momentary aspects, as contextual and psychological factors, regarding the moment of symptom reporting. Regarding abdominal pain, experts concluded that character of abdominal pain is less relevant to be assessed ten times a day. Therefore, it was concluded that severity and location of abdominal pain should be included as the only abdominal painrelating items. Some nuances were added with regard to the GI symptoms, such as besides asking solely for the severity of bloating, it was suggested also to assess whether this is associated with a feeling of discomfort and whether this is accompanied by visible distension of the abdomen. The latter was also mentioned during focus group interviews.

Regarding comorbid symptoms as "feeling tired" and "general illness", as were mentioned during the focus group interviews, experts agreed that those are not suitable for momentary assessments per se. Comorbid symptoms should rather be assessed cross-sectionally, as fatigue and general illness are not likely to change very much during the day. Therefore, those items were not included in the ESM-PROM.

With regard to bowel movements, frequency, stool form and fecal urgency were included as the most important items. Furthermore, straining and (in)complete evacuation were added in case a bowel movement is reported. Other issues regarding defecation were not included. Focus group participants mentioned that it is important to ask whether the severity of abdominal complaints decreased after a bowel movement. However, it was decided that this is not a momentary question and that ESM itself offers the opportunity to evaluate a possible association (relief as well as aggravation of abdominal pain before or following a bowel movement) between bowel movements and abdominal symptoms by repeated measurements over the day.

The ten items regarding psychological status, resulting from focus group interviews, were thoroughly discussed, since experts stated that ten items would be too much of a burden with respect to the time needed to complete one assessment. Therefore, this was reduced to seven items, including both positive and negative affect. Contextual items were discussed as well, but were not changed.

Experts all agreed that nutritional factors are of important interest with regard to IBS symptoms. However, it was discussed that the explicit evaluation of associations between GI symptoms and specific food products is beyond the scope of the current project. Including items on specific nutritional factors would result in too many items. Therefore, it was decided to only include an item on whether or not someone ate between the current and the previous assessment in order to evaluate a possible role for food intake in individual IBS symptomatology. 
With respect to the practical issues that were raised during focus group meetings, several options to change the number of assessments during the day and the time during which an assessment is available after each beep were considered. Since in our pilot study(21) median response time after the signal was 21 seconds (IQR: 11 - 40 seconds) and in only $0.7 \%$ of total assessments response time was longer than 10 minutes, it was decided that extending this time period would probably not result in a much higher response rate. Furthermore, the total compliance rate with ten assessments each day of $76.8 \%$, i.e. on $76.8 \%$ of the total days at least six assessments were completed, was considered high. Therefore, it was decided not to change both of these practical features.

In conclusion, experts' opinions resulted in a further reduction of the number of items to 32 , categorized into the same domains as discussed before. The final instrument, as developed in phase III, is shown in Table S4.

\section{Phase IV: Translations and cognitive interviews}

Demographic characteristics of the participants in each center are shown in Table 1. Cognitive interviews did not reveal any large-scale problems regarding the patients' understanding of the instrument. With respect to the Dutch instrument only a few modifications were suggested in order to verify the patients' understanding. No adjustments were made to the content or the order of the items. The English as well as Swedish instrument needed some modifications with respect to wording after the translation. Also, a few items were adapted to make them more suitable for momentary assessments. Besides these minor changes no alterations of content or order of items were done.

\section{DISCUSSION}

The current study was conducted as part of a multicenter project aiming to develop and validate a new patient-reported assessment tool for real-time evaluation of IBS symptoms. Given the lack of biological markers for IBS, evaluation of potential interventions aimed at symptom 
improvement is dependent on symptom assessments by using patient-reported outcome measures. $(25,38)$ The current lack of a reliable symptom assessment method, that considers all clinically important signs and symptoms of IBS, requires development of a new multi-item tool. $(11,12,29)$

The PROM development in this study was executed according to FDA guidelines and the NIH Patient Reported Outcome Measurement Information System (PROMIS) consortium, recommending PRO instruments to be developed according to a conceptual framework with obtaining patient input to ensure content validity and reliability. $(22,23,25)$ The development was therefore performed in four consecutive phases: initial item selection from literature, obtaining patients' input by structured focus group interviews, considering experts' opinions by an (international) expert meeting and cognitive interviewing with IBS patients after forwardand-back translation.

Focus group interviews revealed a broad spectrum of items that, according to the participants, are relevant for a momentary IBS-specific PROM. After transcription of focus group discussions, a total of 42 items and another 21 optional items were defined. Optional items comprised questions suggested or defined as relevant only by a subset of the participants. All defined items were understandable for the total focus group population, positively contributing to content validity. Since in the experience sampling methodology momentary assessments are collected ten times a day, the number of instrument items should be limited in order to reduce patient burden and thereby maintain patient compliance. Although compliance with ESM was reasonably good (76.8\%) in our pilot study using an ESM instrument containing as much as 60 items, ideally, each assessment should take no longer than 2 minutes.(30) Therefore, selected items were reviewed by an international expert team in the fields of neurogastroenterology and motility, leading to further selection. Finally, a momentary questionnaire containing 32 items was developed.

Items could be clustered into five categories: physical status, defecation, mood and psychological factors, context and environment, and nutrition and drug use. The categories "physical status" (including abdominal symptoms) and "defecation" are the key-elements in actual IBS symptom assessment, whereas the other three categories are aiming to evaluate influencing factors of these symptoms. Specifically, the items covered by "mood and psychological factors" will give insight into a possible link between mental disturbances and IBS symptoms, taking into account the individual moment-to-moment variability of both aspects. Likewise, "context and environment" can be linked to symptom severity, herewith taking into account possible effects of ecological factors on symptom response. "Nutrition and 
drug use" were raised among the most important daily life elements influencing Gl symptoms. To assess the effect of these possible influencing factors on Gl symptoms, multivariate and multilevel analytical techniques will be required. $(30,39)$

Several PROM's for IBS symptom assessment have been developed recently. Spiegel and colleagues delineated a conceptual framework for IBS-PROM's, consisting of 35 items, subdivided over four GI-related domains and an extra-intestinal domain.(23) These five categories are also represented in our ESM-PROM, however, not all individual items have been implemented. All items were discussed during focus group meetings, but given the repeated character of ESM, in particular items regarding symptom-bothersomeness, interference, -impact and -predictability were thought less suitable for the ESM-PROM.

The PROMIS consortium has developed the PROMIS GI symptom scale, which consists of short outcome measures for eight GI symptom complexes.(25) All symptom complexes, but 'disrupted swallowing' and 'bowel incontinence/soilage', are taken into account in the ESMPROM. Focus groups revealed that problems with swallowing are not very frequently encountered in the context of IBS. Bowel incontinence might occur, but was not reported by the majority of IBS patients and was therefore thought not generalizable to the target population of the ESM-PROM.

Recently, the 'Diary for Irritable Bowel Syndrome Symptoms' was developed by the PatientReported Outcome Consortium IBS Working Group (PRO Consortium IBS-WG).(40) The conceptual framework for this 24-hour diary is based on two core symptoms: abdominal symptoms and bowel movement-related symptoms. Of the elicited specific items, abdominal discomfort and abdominal cramping are not included in our ESM-PROM, since these were found difficult to differentiate from abdominal pain - in line with recent Rome IV definitions. Therefore, these items will not add considerable extra information and were omitted in order to reduce the number of items.

All in all, the differences between the ESM-PROM and previously developed PROM's for IBS mainly relate to differences in methodology and the fact that ESM concerns repeated assessments over the day.

Next to the items, also possible scoring scales for all items were discussed. Participants supported the use of a Numeric Rating Scale, but could not agree on seven (as formerly used in ESM (30)) or eleven endpoints. In comparison, the PROMIS scales make use of a 5-point Likert scale (41), however, an end-of-day 11-point NRS is currently recommended by the FDA and EMA (European Medicines Agency) as a primary endpoint in IBS clinical trials $(11,12)$. In order to prevent confusion by using different response scales, this scale was chosen to be incorporated into the instrument for all items. 
A number of study limitations ought to be noted. First, the risk of self-selection (sampling) bias, i.e. the participants' decision whether or not to participate may influence the representativeness of the study population. As an example, subjects with a stronger opinion than others or with more severe symptoms might be more willing to participate in the focus group meetings. Furthermore, only 53\% (17/32) of the initially attending participants of the focus groups did eventually participate. However, since the Maastricht IBS cohort concludes a large heterogeneous IBS population, we expect to cover this heterogeneity even in this small subset of the population. Additionally, possible differences between subjects who did participate in the focus group meetings and subjects who did not, were explored. As shown in Table S1 no statistically significant differences in demographical characteristics or symptom severity scores, possibly indicating self-selection bias, were demonstrated. It appears that focus group participants less often scored positive for depressive symptoms on the HADS, using a cut-off of $\geq 8$, and showed a slightly higher Mental Composite Score on the SF-36, than the subjects who did not participate in focus group meetings. Though these differences were not statistically significant, this may indicate that the focus group population did not perfectly reflect the heterogeneity of the general IBS population with regard to mental health. However, since the HADS is a screening tool using a cut-off value, a score $<8$ does not mean that no depressive symptoms were present in our population at all. Furthermore, participants agreed on the importance of assessing psychological factors additionally to Gl symptoms, and therefore, we are confident that the content of the developed ESM-PROM includes the relevant questions for symptom assessment in IBS patients. Another limitation might be the distribution of IBS subtypes amongst the participants, since only $12 \%(2 / 17)$ of subjects were defined as constipation-predominant IBS (IBS-C). Nevertheless, we believe that constipation-associated symptoms will as well be experienced by mixed-type (IBS-M) patients and so, we expect to have captured both diarrhea- and constipation-associated symptoms. Also, during the cognitive interviews IBS-C patients were attending and did not mention a lack of any constipation-specific items.

The number of subjects attending focus group meetings should be mentioned. The relatively small number of participants per focus group (i.e. 6-8) was chosen, since it is considered to invite all subjects to actively participate in the discussion on the one hand and to gain a variety of perspectives on the other hand.(42) Furthermore, as discussed previously in this report, focus group meetings were arranged one by one until reaching saturation of input after four meetings and therefore, we feel that the total sample of 17 participants suffices with regard to this project. To date, successful focus group studies with similar sample sizes have been reported previously. $(35,43)$ Likewise, rather small numbers of participants were included for 
the cognitive interviews in each center, however, also in this phase of the project saturation of input was ensured. Since focus groups and the expert meeting already determined the content of the tool, cognitive interviews were particularly intended to evaluate patients' understanding with the individual items of the ESM-PROM with regard to linguistic issues (i.e. after forwardand-back translation). Therefore, the resulting number of cognitive interviews per center meets our expectations. With regard to level of education and employment status, the Dutch participants reflect the general Dutch population quite well. The Swedish and English participants were, however, relatively highly educated. This should be taken into account when recruiting subjects for future studies regarding the developed questionnaire, since extra instructions on how to interpret and answer the questions might be needed in lower educated individuals.

In conclusion, we here report on the development of a disease-targeted PROM suitable for real-time assessment of abdominal pain and other gastrointestinal symptoms as well as daily life factors that may influence IBS symptoms. A smartphone application has been specifically developed to implement this PROM and future research will comprise further, multicenter validation of this instrument, with regard to the different languages and cross-cultural aspects. ESM appears particularly suitable for the evaluation of individual symptom patterns over the course of a predefined period of time and the identification of specific triggers of gastrointestinal symptoms in daily life. It can hereby function in supporting diagnostic as well as therapeutic trajectories, in clinical practice. Moreover, once ESM is demonstrated to be a valid and reliable PRO instrument in this particular context, it can be implemented in clinical research to assess the effect of therapeutic interventions in IBS and to stratify IBS patients based on their symptoms. 


\section{ACKNOWLEDGMENTS}

\section{AUTHOR CONTRIBUTIONS}

Study concept and design: LV, DK, ZM, JK, CL, JO, AM; Focus group interviewing: LV, DK, ZM; Expert meeting: LV, DK, JK, CL, MS, QA, MC, JT, SR, EQ, DD, AM; Cognitive interviewing: LV, IP, HT, AS, LH; Manuscript writing: LV; Constructive review of manuscript: DK, ZM, JK, CL, IP, HT, MS, AS, AQ, MC, JT, SR, EQ, DD, AM.

\section{FUNDING}

This study is investigator initiated and partly financially supported by Grünenthal $\mathrm{GmBH}$, Aachen, Germany.

\section{DISCLOSURES}

D. Keszthelyi and A.A.M. Masclee have received funding for research from Grünenthal GmBH.

H. Törnblom has served as Consultant/Advisory Board member for Almirall and Allergan and as a speaker for Tillotts, Takeda, Shire and Almirall. M. Simrén has received unrestricted research grants from Danone, and Ferring Pharmaceuticals, and served as a Consultant/Advisory Board member for AstraZeneca, Danone, Nestlé, Almirall, Allergan, Albireo, Glycom, and Shire, and as a speaker for Tillotts, Menarini, Takeda, Shire and Almirall. E.G. Quetglas is an employee of Grünenthal $\mathrm{GmBH}$. 


\section{SUPPORTING INFORMATION}

Table S1. Demographical characteristics and symptom severity scores of participants of the Maastricht IBS-cohort, separate for 'focus group participation' versus 'no focus group participation'.

Table S2. Set of items for the ESM-PROM developed during phase I: Initial item selection.

Table S3. Set of items for the ESM-PROM, adjusted according to patients' input during phase II: Focus group interviews.

Table S4. Set of items for the ESM-PROM, adjusted according to experts' input during phase III: Expert meeting. 


\section{REFERENCES}

1. Choung RS, Locke GR, 3rd. Epidemiology of IBS. Gastroenterology clinics of North America. 2011;40(1):1-10.

2. Grundmann O, Yoon SL. Irritable bowel syndrome: epidemiology, diagnosis and treatment: an update for health-care practitioners. Journal of gastroenterology and hepatology. 2010;25(4):691-9.

3. Camilleri M, Lasch K, Zhou W. Irritable bowel syndrome: methods, mechanisms, and pathophysiology. The confluence of increased permeability, inflammation, and pain in irritable bowel syndrome. American journal of physiology Gastrointestinal and liver physiology. 2012;303(7):G775-85.

4. Lovell RM, Ford AC. Global prevalence of and risk factors for irritable bowel syndrome: a metaanalysis. Clinical gastroenterology and hepatology : the official clinical practice journal of the American Gastroenterological Association. 2012;10(7):712-21.e4.

5. Canavan C, West J, Card T. Review article: the economic impact of the irritable bowel syndrome. Alimentary pharmacology \& therapeutics. 2014;40(9):1023-34.

6. Simren M, Brazier J, Coremans G, Dapoigny M, Muller-Lissner SA, Pace F, et al. Quality of life and illness costs in irritable bowel syndrome. Digestion. 2004;69(4):254-61.

7. Drossman DA. The functional gastrointestinal disorders and the Rome III process. Gastroenterology. 2006;130(5):1377-90.

8. Longstreth GF, Thompson WG, Chey WD, Houghton LA, Mearin F, Spiller RC. Functional bowel disorders. Gastroenterology. 2006;130(5):1480-91.

9. Ford AC, Bercik P, Morgan DG, Bolino C, Pintos-Sanchez MI, Moayyedi P. Validation of the Rome III criteria for the diagnosis of irritable bowel syndrome in secondary care. Gastroenterology. 2013;145(6):1262-70.e1.

10. Mearin F, Lacy BE, Chang L, Chey WD, Lembo AJ, Simren M, et al. Bowel Disorders. Gastroenterology. 2016.

11. U.S. Department of Health and Human Services FaDA, Center for Drug Evaluation and Research (CDER). Guidance for Industry Irritable Bowel Syndrome - Clinical Evaluation of Drugs for Treatment2012.

12. (EMA) EMA. Guideline on the evaluation of medicinal products for the treatment of irritable bowel syndrome2014.

13. Shiffman S, Stone AA, Hufford MR. Ecological momentary assessment. Annual review of clinical psychology. 2008;4:1-32.

14. Myin-Germeys I, Oorschot M, Collip D, Lataster J, Delespaul P, van Os J. Experience sampling research in psychopathology: opening the black box of daily life. Psychological medicine. 2009;39(9):1533-47.

15. Houtveen $\mathrm{JH}$, Oei NY. Recall bias in reporting medically unexplained symptoms comes from semantic memory. Journal of psychosomatic research. 2007;62(3):277-82.

16. Moskowitz DS, Young SN. Ecological momentary assessment: what it is and why it is a method of the future in clinical psychopharmacology. Journal of psychiatry \& neuroscience : JPN. 2006;31(1):13-20.

17. Jamison RN, Raymond SA, Levine JG, Slawsby EA, Nedeljkovic SS, Katz NP. Electronic diaries for monitoring chronic pain: 1-year validation study. Pain. 2001;91(3):277-85.

18. Stone AA, Broderick JE, Schwartz JE, Shiffman S, Litcher-Kelly L, Calvanese P. Intensive momentary reporting of pain with an electronic diary: reactivity, compliance, and patient satisfaction. Pain. 2003;104(1-2):343-51.

19. Stone AA, Broderick JE, Shiffman SS, Schwartz JE. Understanding recall of weekly pain from a momentary assessment perspective: absolute agreement, between- and within-person consistency, and judged change in weekly pain. Pain. 2004;107(1-2):61-9.

20. Weinland SR, Morris CB, Hu Y, Leserman J, Bangdiwala SI, Drossman DA. Characterization of episodes of irritable bowel syndrome using ecological momentary assessment. The American journal of gastroenterology. 2011;106(10):1813-20. 
21. Mujagic Z, Leue C, Vork L, Lousberg R, Jonkers DM, Keszthelyi D, et al. The Experience Sampling Method--a new digital tool for momentary symptom assessment in IBS: an exploratory study. Neurogastroenterology and motility : the official journal of the European Gastrointestinal Motility Society. 2015;27(9):1295-302.

22. U.S. Department of Health and Human Services FaDA, Center for Drug Evaluation and Research (CDER), Center for Biologics Evaluation and Research (CBER), Center for Devices and Radiological Health (CDRH). Guidance for Industry Patient-Reported Outcome Measures: Use in Medical Product Development to Support Labeling Claims. 2009.

23. Spiegel BM, Bolus R, Agarwal N, Sayuk G, Harris LA, Lucak S, et al. Measuring symptoms in the irritable bowel syndrome: development of a framework for clinical trials. Alimentary pharmacology \& therapeutics. 2010;32(10):1275-91.

24. Spiegel BM, Bolus R, Harris LA, Lucak S, Chey WD, Sayuk G, et al. Characterizing abdominal pain in IBS: guidance for study inclusion criteria, outcome measurement and clinical practice. Alimentary pharmacology \& therapeutics. 2010;32(9):1192-202.

25. Spiegel BM, Hays RD, Bolus R, Melmed GY, Chang L, Whitman C, et al. Development of the NIH Patient-Reported Outcomes Measurement Information System (PROMIS) gastrointestinal symptom scales. The American journal of gastroenterology. 2014;109(11):1804-14.

26. Marquis P, Lasch KE, Delgado-Herrera L, Kothari S, Lembo A, Lademacher C, et al. Qualitative development of a patient-reported outcome symptom measure in diarrhea-predominant irritable bowel syndrome. Clinical and translational gastroenterology. 2014;5:e59.

27. Wiklund IK, Fullerton S, Hawkey CJ, Jones RH, Longstreth GF, Mayer EA, et al. An irritable bowel syndrome-specific symptom questionnaire: development and validation. Scandinavian journal of gastroenterology. 2003;38(9):947-54.

28. Labus JS, Bolus R, Chang L, Wiklund I, Naesdal J, Mayer EA, et al. The Visceral Sensitivity Index: development and validation of a gastrointestinal symptom-specific anxiety scale. Alimentary pharmacology \& therapeutics. 2004;20(1):89-97.

29. Mujagic Z, Keszthelyi D, Aziz Q, Reinisch W, Quetglas EG, De Leonardis F, et al. Systematic review: instruments to assess abdominal pain in irritable bowel syndrome. Alimentary pharmacology \& therapeutics. 2015;42(9):1064-81.

30. Verhagen SJ, Hasmi L, Drukker M, van Os J, Delespaul PA. Use of the experience sampling method in the context of clinical trials. Evidence-based mental health. 2016;19(3):86-9.

31. Delespaul P. Assessing schizophrenia in daily life the experience sampling method.: UPM, Universitaire Pers Maastricht, Maastricht University; 1995.

32. Ludidi S, Mujagic Z, Jonkers D, Keszthelyi D, Hesselink M, Kruimel J, et al. Markers for visceral hypersensitivity in patients with irritable bowel syndrome. Neurogastroenterology and motility : the official journal of the European Gastrointestinal Motility Society. 2014;26(8):1104-11.

33. Mujagic Z, Ludidi S, Keszthelyi D, Hesselink MA, Kruimel JW, Lenaerts K, et al. Small intestinal permeability is increased in diarrhoea predominant IBS, while alterations in gastroduodenal permeability in all IBS subtypes are largely attributable to confounders. Alimentary pharmacology \& therapeutics. 2014;40(3):288-97.

34. Morgan DL. The Focus Group Guidebook. California: Sage Publications; 1998.

35. Drossman DA, Chang L, Schneck S, Blackman C, Norton WF, Norton NJ. A focus group assessment of patient perspectives on irritable bowel syndrome and illness severity. Digestive diseases and sciences. 2009;54(7):1532-41.

36. A. KR. Moderating Focus Groups. California: Sage Publications; 1998.

37. (WHO) WHO. Process of translation and adaptation of instruments 2015 [Available from: http://www.who.int/substance_abuse/research_tools/translation/en/.

38. Alrubaiy L, Hutchings HA, Williams JG. Assessing patient reported outcome measures: A practical guide for gastroenterologists. United European gastroenterology journal. 2014;2(6):463-70.

39. Myin-Germeys I, Peeters F, Havermans R, Nicolson NA, DeVries MW, Delespaul P, et al. Emotional reactivity to daily life stress in psychosis and affective disorder: an experience sampling study. Acta psychiatrica Scandinavica. 2003;107(2):124-31. 
40. Fehnel SE, Ervin CM, Carson RT, Rigoni G, Lackner JM, Coons SJ. Development of the Diary for Irritable Bowel Syndrome Symptoms to Assess Treatment Benefit in Clinical Trials: Foundational Qualitative Research. Value in health : the journal of the International Society for Pharmacoeconomics and Outcomes Research. 2017;20(4):618-26.

41. DeWalt DA, Rothrock N, Yount S, Stone AA. Evaluation of item candidates: the PROMIS qualitative item review. Medical care. 2007;45(5 Suppl 1):S12-21.

42. Rabiee F. Focus-group interview and data analysis. The Proceedings of the Nutrition Society. 2004;63(4):655-60.

43. Carbone F, Holvoet L, Vandenberghe A, Tack J. Functional dyspepsia: outcome of focus groups for the development of a questionnaire for symptom assessment in patients suffering from postprandial distress syndrome (PDS). Neurogastroenterology and motility : the official journal of the European Gastrointestinal Motility Society. 2014;26(9):1266-74.

44. Ostrom C, Bair E, Maixner W, Dubner R, Fillingim RB, Ohrbach R, et al. Demographic Predictors of Pain Sensitivity: Results From the OPPERA Study. The journal of pain : official journal of the American Pain Society. 2017;18(3):295-307.

45. Edwards RR, Doleys DM, Fillingim RB, Lowery D. Ethnic differences in pain tolerance: clinical implications in a chronic pain population. Psychosomatic medicine. 2001;63(2):316-23. 


\section{TABLES}

Table 1: Patient characteristics of subjects that participated in the different phases of the project.

\begin{tabular}{|c|c|c|c|c|}
\hline & $\begin{array}{c}\text { Focus group } \\
\text { interviews } \\
\text { Netherlands } \\
\quad \mathrm{N}=17\end{array}$ & $\begin{array}{c}\text { Cognitive } \\
\text { interviews, } \\
\text { Netherlands } \\
\quad \mathrm{N}=5\end{array}$ & $\begin{array}{c}\text { Cognitive } \\
\text { interviews, } \\
\text { Sweden } \\
\mathrm{N}=6\end{array}$ & $\begin{array}{c}\text { Cognitive } \\
\text { interviews, } \\
\text { UK } \\
\mathrm{N}=6\end{array}$ \\
\hline Age, median [IQR] & $58.0[39.5-63.0]$ & $49[24.5-57.5]$ & $37.5[31.0-64.25]$ & $34[22.5-44.0]$ \\
\hline Female, $\mathrm{n}(\%)$ & $13(76.5)$ & $4(80)$ & $3(50)$ & $3(50)$ \\
\hline $\begin{array}{l}\text { IBS-subtype, n (\%) } \\
\text { IBS-D } \\
\text { IBS-C } \\
\text { IBS-M } \\
\text { IBS-U }\end{array}$ & $\begin{array}{c}8(47.0) \\
2(11.8) \\
7(41.2) \\
0\end{array}$ & $\begin{array}{c}2(40) \\
2(40) \\
1(20) \\
0\end{array}$ & $\begin{array}{c}0 \\
2(33.3) \\
4(66.7) \\
0\end{array}$ & $\begin{array}{c}2(33.3)^{\#} \\
1(16.7)^{\#} \\
1(16.7)^{\#} \\
0 \#\end{array}$ \\
\hline $\begin{array}{l}\text { Level of education } \\
\text { Primary } \\
\text { Secondary } \\
\text { University }\end{array}$ & $\begin{array}{c}1(5.9)^{\#} \\
12(70.6) \# \\
2(11.8)^{\#}\end{array}$ & $4(80.0)$ \# & $6(100)$ & $\begin{array}{l}1(16.7) \\
5(83.3)\end{array}$ \\
\hline $\begin{array}{l}\text { Work status } \\
\text { School/student } \\
\text { Employed } \\
\text { Unemployed } \\
\text { Retired }\end{array}$ & $\begin{array}{l}8(47.1)^{\#} \\
4(23.5)^{\#} \\
3(17.6)^{\#}\end{array}$ & $\begin{array}{l}2(40.0)^{\#} \\
2(40.0)^{\#}\end{array}$ & $5(83.3) \#$ & $\begin{array}{l}\# \\
\# \\
\# \\
\#\end{array}$ \\
\hline
\end{tabular}

\# Data of other participants are missing. 


\section{FIGURES}

Figure 1: Framework of the developed PROM, consisting of 25 items (in the figure summarized in 10 constructs) based on five domains.

Figure 2: Picture on which subjects can indicate the location of abdominal pain according to nine abdominal regions. 
Table S1: Demographical characteristics and symptom severity scores of participants of the Maastricht IBScohort, separate for 'focus group participation' versus 'no focus group participation'.

\begin{tabular}{|c|c|c|}
\hline \multicolumn{3}{|l|}{ Maastricht IBS Cohort } \\
\hline & $\begin{array}{l}\text { Focus group participation } \\
(n=17)\end{array}$ & $\begin{array}{l}\text { No focus group participation } \\
(\mathrm{n}=412)\end{array}$ \\
\hline Female sex, $\mathrm{n}(\%)$ & $13(76.5)$ & $295(71.6)$ \\
\hline Age, median [IQR] & $58.0[39.5-63.0]$ & $45.0[28.0-59.0]^{*}$ \\
\hline BMI, median [IQR] & $26.5[22.2-30.9]$ & $24.1[21.5-27.4]$ \\
\hline \multicolumn{3}{|l|}{ IBS Subtype, n (\%) } \\
\hline IBS-D & $8(47.1)$ & $135(32.8)$ \\
\hline IBS-C & $2(11.8)$ & $82(19.9)$ \\
\hline IBS-M & $7(41.2)$ & $169(41.0)$ \\
\hline IBS-U & 0 & $26 \quad(6.3)$ \\
\hline \multicolumn{3}{|l|}{$\begin{array}{l}\text { 14-day mean symptom score, } \\
\text { median }[\mathrm{IQR}]\end{array}$} \\
\hline Abdominal pain & $2.14[1.64-2.64]$ & $2.21[1.57-2.86]$ \\
\hline Abdominal discomfort & $2.29[2.04-2.69]$ & $2.36[1.92-2.93]$ \\
\hline Abdominal bloating & $2.07[1.72-2.46]$ & $2.09[1.50-2.86]$ \\
\hline Constipation & $1.07[1.00-1.59]$ & $1.29[1.00-1.89]$ \\
\hline Diarrhea & $1.14[1.00-1.48]$ & $1.21[1.07-1.67]$ \\
\hline \multicolumn{3}{|l|}{ HADS, n (\%) } \\
\hline Depression $\geq 8$ & $1(5.9)$ & $86(20.9)$ \\
\hline Anxiety $\geq 8$ & $5(29.4)$ & $154(37.4)$ \\
\hline \multicolumn{3}{|l|}{ SF-36, median [IQR] } \\
\hline Physical Composite Score (PCS) & $41.21[36.05-53.18]$ & $42.63[33.99-49.60]$ \\
\hline Mental Composite Score (MCS) & 54.34 [47.30 - 56.97] & $48.67[39.85-55.41]$ \\
\hline
\end{tabular}

Differences tested using Mann-Whitney $U$ test for continuous data and $X^{2}$ - or Fisher's exact test for categorical data.

* Significant difference between 'focus group participation' and 'no focus group participation' $(p<0.05)$. 
Table S2: Set of items for the ESM-PROM developed during phase I: Initial item selection.

\begin{tabular}{|c|c|c|}
\hline \multicolumn{3}{|c|}{ Phase I: Initial item selection } \\
\hline \multicolumn{2}{|r|}{ Physical status } & Answer scale \\
\hline 1 & I feel hungry & 1 (none) - 7 (very much) \\
\hline 2 & I feel tired & 1 (none) - 7 (very much) \\
\hline 3 & I do not feel well & 1 (none) - 7 (very much) \\
\hline 4 & I am having palpitations & 1 (none) - 7 (very much) \\
\hline 5 & I am sweating & 1 (none) - 7 (very much) \\
\hline 6 & I feel numbness/tingling & 1 (none) - 7 (very much) \\
\hline 7 & I am short of breath & 1 (none) - 7 (very much) \\
\hline 8 & I have a choking sensation & 1 (none) - 7 (very much) \\
\hline 9 & I feel chest pain & 1 (none) - 7 (very much) \\
\hline 10 & I feel dizzy & 1 (none) - 7 (very much) \\
\hline 11 & I am having hot flashes & 1 (none) - 7 (very much) \\
\hline 12 & I am having chills & 1 (none) - 7 (very much) \\
\hline 13 & I feel upper abdominal pain & 1 (none) - 7 (very much) \\
\hline 14 & I feel lower abdominal pain & 1 (none) - 7 (very much) \\
\hline 15 & I am feeling heartburn & 1 (none) - 7 (very much) \\
\hline 16 & I am feeling sick & 1 (none) - 7 (very much) \\
\hline 17 & I feel bloated & 1 (none) - 7 (very much) \\
\hline 18 & I am having intestinal gas & 1 (none) - 7 (very much) \\
\hline 19 & I am suffering from burping & 1 (none) - 7 (very much) \\
\hline 20 & $\begin{array}{l}\text { I have been physically active since the previous beep } \\
\text { signal }\end{array}$ & 1 (none) - 7 (very much) \\
\hline \multicolumn{3}{|c|}{ Defecation } \\
\hline 21 & Have you defecated since the previous beep signal? & Yes / No \\
\hline 22 & If yes, what did the stool look like? & Bristol Stool Score 1 - 7 \\
\hline \multicolumn{3}{|c|}{ Mood } \\
\hline 23 & I feel enthusiastic & 1 (none) - 7 (very much) \\
\hline 24 & I feel sad & 1 (none) - 7 (very much) \\
\hline 25 & I feel irritated & 1 (none) - 7 (very much) \\
\hline 26 & I feel content & 1 (none) - 7 (very much) \\
\hline 27 & I feel stressed & 1 (none) - 7 (very much) \\
\hline 28 & I feel restless & 1 (none) - 7 (very much) \\
\hline 29 & I feel happy & 1 (none) - 7 (very much) \\
\hline 30 & I feel lonely & 1 (none) - 7 (very much) \\
\hline 31 & I feel strong & 1 (none) - 7 (very much) \\
\hline 32 & I feel anxious & 1 (none) - 7 (very much) \\
\hline 33 & I feel relaxed & 1 (none) - 7 (very much) \\
\hline 34 & I feel worried & 1 (none) - 7 (very much) \\
\hline 35 & I feel inspired & 1 (none) - 7 (very much) \\
\hline 36 & I feel disappointed & 1 (none) - 7 (very much) \\
\hline 37 & I feel insecure & 1 (none) - 7 (very much) \\
\hline 38 & I feel cheerful & 1 (none) - 7 (very much) \\
\hline 39 & I feel guilty & 1 (none) - 7 (very much) \\
\hline
\end{tabular}




\begin{tabular}{|c|c|c|}
\hline \multicolumn{3}{|c|}{ Mood (continued) } \\
\hline 40 & I am afraid to lose self-control & 1 (none) - 7 (very much) \\
\hline 41 & I can not drop my thoughts & 1 (none) - 7 (very much) \\
\hline 42 & I am worrying & 1 (none) - 7 (very much) \\
\hline 43 & Overall, I feel good & 1 (none) - 7 (very much) \\
\hline \multicolumn{3}{|c|}{ Environmental and social context } \\
\hline 44 & Where am I? & $\begin{array}{l}\text { At home, at someone } \\
\text { else's house, work/school, } \\
\text { public place, on the go, } \\
\text { somewhere else }\end{array}$ \\
\hline 45 & Who is with me? & $\begin{array}{l}\text { Partner, friends, residents, } \\
\text { colleagues, family (not } \\
\text { residents), acquaintances, } \\
\text { unknown/others, nobody }\end{array}$ \\
\hline 46 & I find their company pleasant & 1 (none) - 7 (very much) \\
\hline 47 & I feel accepted & 1 (none) - 7 (very much) \\
\hline 48 & I feel uncomfortable in this situation & 1 (none) - 7 (very much) \\
\hline 49 & I would rather be alone & 1 (none) - 7 (very much) \\
\hline 50 & We are doing something together & 1 (none) - 7 (very much) \\
\hline 51 & What am I doing (right before the beep)? & $\begin{array}{l}\text { Resting, work/school, } \\
\text { housekeeping/grocery, } \\
\text { hygiene/self-care, } \\
\text { eating/drinking, relaxing, } \\
\text { something else }\end{array}$ \\
\hline 52 & I would rather like to do something else & 1 (none) - 7 (very much) \\
\hline 53 & I am active right now & 1 (none) - 7 (very much) \\
\hline 54 & I like to do this activity & 1 (none) - 7 (very much) \\
\hline 55 & It takes effort to do this & 1 (none) - 7 (very much) \\
\hline 56 & I am good at this & 1 (none) - 7 (very much) \\
\hline \multirow[t]{2}{*}{57} & This is a challenge for me & 1 (none) - 7 (very much) \\
\hline & \multicolumn{2}{|c|}{ Think of the most important event since the previous beep signal: } \\
\hline 58 & This event was: & $\begin{array}{l}-3 \text { (very unpleasant) - } \\
3 \text { (very pleasant) }\end{array}$ \\
\hline 59 & This event was: & $\begin{array}{l}-3 \text { (very unimportant) - } \\
3 \text { (very important) }\end{array}$ \\
\hline \multicolumn{3}{|c|}{ Drug use } \\
\hline 60 & I used ... since the previous beep signal & $\begin{array}{l}\text { Caffeine, nicotine, } \\
\text { medication, alcohol, } \\
\text { cannabis, other drugs, } \\
\text { none of those }\end{array}$ \\
\hline
\end{tabular}

Red color indicates items that were removed from the instrument during phase II: Focus group interviews. 
Table S3: Set of items for the ESM-PROM, adjusted according to patients' input during phase II: Focus group interviews.

\begin{tabular}{|c|c|c|}
\hline \multicolumn{3}{|c|}{ Phase II: Focus group interviews } \\
\hline & Physical status & Answer scale \\
\hline 1 & I feel hungry & 0 (none) - 10 (very much) \\
\hline 2 & I feel tired & 0 (none) - 10 (very much) \\
\hline 3 & I am having palpitations & 0 (none) - 10 (very much) \\
\hline 4 & I am sweating & 0 (none) - 10 (very much) \\
\hline 5 & I am short of breath & 0 (none) - 10 (very much) \\
\hline 6 & I feel dizzy & 0 (none) - 10 (very much) \\
\hline 7 & I am having abdominal pain & 0 (none) - 10 (very much) \\
\hline $7 a$ & $\begin{array}{l}\text { This pain is located in the following part(s) of my } \\
\text { abdomen }\end{array}$ & Figure abdominal regions \\
\hline 8 & I am feeling heartburn & 0 (none) - 10 (very much) \\
\hline 9 & I am feeling sick & 0 (none) - 10 (very much) \\
\hline 10 & My abdomen feels bloated & 0 (none) - 10 (very much) \\
\hline 11 & I am having intestinal gas & 0 (none) - 10 (very much) \\
\hline 12 & I am suffering from burping & 0 (none) - 10 (very much) \\
\hline 13 & $\begin{array}{l}\text { I am having rumbling sounds coming from my } \\
\text { abdomen }\end{array}$ & 0 (none) - 10 (very much) \\
\hline 14 & $\begin{array}{l}\text { I have been physically active since the previous beep } \\
\text { signal }\end{array}$ & 0 (none) - 10 (very much) \\
\hline \multicolumn{3}{|c|}{ Defecation } \\
\hline 15 & $\begin{array}{l}\text { How many times did you open your bowels since the } \\
\text { previous beep signal? }\end{array}$ & $\begin{array}{l}0,1,2,3,4, \text { more than } 4 \\
\text { times }\end{array}$ \\
\hline 16 & What did the stool look like? & Bristol Stool Score 1 - 7 \\
\hline 17 & $\begin{array}{l}\text { I have felt an urge to open my bowel since the } \\
\text { previous beep signal }\end{array}$ & 0 (none) - 10 (very much) \\
\hline 18 & $\begin{array}{l}\text { The bowel movement(s) was/were associated with a } \\
\text { relief of my abdominal symptoms }\end{array}$ & 0 (none) - 10 (very much) \\
\hline 19 & $\begin{array}{l}\text { I have been able to postpone a bowel movement since } \\
\text { the previous beep signal }\end{array}$ & 0 (none) - 10 (very much) \\
\hline \multicolumn{3}{|c|}{ Mood and psychological factors } \\
\hline 20 & I feel sad & 0 (none) - 10 (very much) \\
\hline 21 & I feel irritated & 0 (none) - 10 (very much) \\
\hline 22 & I feel content & 0 (none) - 10 (very much) \\
\hline 23 & I feel stressed & 0 (none) - 10 (very much) \\
\hline 24 & I feel lonely & 0 (none) - 10 (very much) \\
\hline 25 & I feel anxious & 0 (none) - 10 (very much) \\
\hline 26 & I feel relaxed & 0 (none) - 10 (very much) \\
\hline 27 & I feel insecure & 0 (none) - 10 (very much) \\
\hline 28 & I feel cheerful & 0 (none) - 10 (very much) \\
\hline 29 & I am worrying & 0 (none) - 10 (very much) \\
\hline
\end{tabular}




\begin{tabular}{|c|c|c|}
\hline \multicolumn{3}{|c|}{ Context and environment } \\
\hline 30 & Where am I? & $\begin{array}{l}\text { At home, at someone } \\
\text { else's house, work/school, } \\
\text { public place, on the go, } \\
\text { somewhere else }\end{array}$ \\
\hline 31 & Who is with me? & $\begin{array}{l}\text { Partner, friends, residents, } \\
\text { colleagues, family (not } \\
\text { residents), acquaintances, } \\
\text { unknown/others, nobody }\end{array}$ \\
\hline 32 & I find this company (un)pleasant & $\begin{array}{l}-5 \text { (very unpleasant) }-5 \\
\text { (very pleasant) }\end{array}$ \\
\hline 33 & I find this situation (un)pleasant & $\begin{array}{l}-5 \text { (very unpleasant })-5 \\
\text { (very pleasant) }\end{array}$ \\
\hline 34 & I feel (un)comfortable in this situation & $\begin{array}{l}-5 \text { (very uncomfortable) - } \\
5 \text { (very comfortable) }\end{array}$ \\
\hline 35 & What am I doing (right before the beep)? & $\begin{array}{l}\text { Resting, work/school, } \\
\text { housekeeping/grocery, } \\
\text { hygiene/self-care, } \\
\text { eating/drinking, relaxing, } \\
\text { sports, something else }\end{array}$ \\
\hline 36 & I like to do this activity & 0 (none) - 10 (very much) \\
\hline 37 & $\begin{array}{l}\text { My complaints restrict me in doing my normal activities } \\
\text { right now }\end{array}$ & 0 (none) - 10 (very much) \\
\hline & $\begin{array}{l}\text { Think of the most important event since the previous } \\
\text { beep signal: }\end{array}$ & \\
\hline 38 & This event was: & $\begin{array}{l}-5 \text { (very unpleasant) }-5 \\
\text { (very pleasant) }\end{array}$ \\
\hline 39 & This event was: & $\begin{array}{l}-5 \text { (very unimportant) }-5 \\
\text { (very important) }\end{array}$ \\
\hline \multicolumn{3}{|c|}{ Nutrition and drug use } \\
\hline 40 & I used ... since the previous beep signal & $\begin{array}{l}\text { Caffeine (coffee) / theine } \\
\text { (tea), nicotine (smoking), } \\
\text { medication, alcohol, drugs, } \\
\text { none of those }\end{array}$ \\
\hline $40 a$ & This was following medication: & $\begin{array}{l}\text { Medication for abdominal } \\
\text { pain, other pain relief, } \\
\text { medication for stomach } \\
\text { acidity, medication for } \\
\text { nausea, medication to } \\
\text { stop diarrhea, medication } \\
\text { for constipation, } \\
\text { something else }\end{array}$ \\
\hline 41 & I ate ... since the previous beep signal & $\begin{array}{l}\text { Wheat, spicy food, fatty } \\
\text { food, cabbage/leek/onion, } \\
\text { dairy products, none of } \\
\text { these }\end{array}$ \\
\hline 42 & I ate .. ago & $\begin{array}{l}\text { Less than } 15 \mathrm{~min} ; 15-30 \\
\text { min; } 30 \text { min-1 hr; } \\
\text { more than1 hr }\end{array}$ \\
\hline
\end{tabular}

Green color indicates items that were newly added to the instrument during phase II: Focus group interviews. Red color indicates items that were removed from the instrument during phase III: Expert meeting. 
Table S4: Set of items for the ESM-PROM, adjusted according to experts' input during phase III: Expert meeting.

\begin{tabular}{|c|c|c|}
\hline \multicolumn{3}{|c|}{ Phase III: Expert meeting } \\
\hline \multicolumn{2}{|r|}{ Physical status } & Answer scale \\
\hline 1 & I am having abdominal pain & 0 (none) - 10 (very much) \\
\hline $1 \mathrm{a}$ & $\begin{array}{l}\text { This pain is located in the following part(s) of my } \\
\text { abdomen: }\end{array}$ & Figure abdominal regions \\
\hline 2 & I am having intestinal gas & 0 (none) - 10 (very much) \\
\hline $2 a$ & The intestinal gas is causing discomfort & 0 (none) - 10 (very much) \\
\hline 3 & $\begin{array}{l}\text { I am having rumbling sounds coming from my } \\
\text { abdomen }\end{array}$ & 0 (none) - 10 (very much) \\
\hline 4 & My abdomen feels bloated & 0 (none) - 10 (very much) \\
\hline $4 a$ & The bloating makes me feel uncomfortable & 0 (none) - 10 (very much) \\
\hline $4 b$ & The bloating is accompanied by a swollen abdomen & 0 (none) - 10 (very much) \\
\hline 5 & I have the urge to open my bowels & 0 (none) - 10 (very much) \\
\hline 6 & I am feeling sick & 0 (none) - 10 (very much) \\
\hline 7 & I am suffering from burping & 0 (none) - 10 (very much) \\
\hline 8 & I am feeling heartburn & 0 (none) - 10 (very much) \\
\hline 9 & I am feeling full & 0 (none) - 10 (very much) \\
\hline 10 & I am having palpitations & 0 (none) - 10 (very much) \\
\hline 11 & I am sweating & 0 (none) - 10 (very much) \\
\hline 12 & I am short of breath & 0 (none) - 10 (very much) \\
\hline 13 & I feel dizzy & 0 (none) - 10 (very much) \\
\hline 14 & My muscles are hurting & 0 (none) - 10 (very much) \\
\hline 15 & My joints are hurting & 0 (none) - 10 (very much) \\
\hline 16 & I feel an urge to pass urine & 0 (none) - 10 (very much) \\
\hline \multicolumn{3}{|c|}{ Defecation } \\
\hline 17 & $\begin{array}{l}\text { Since the last beep, I have had the feeling that I had } \\
\text { to open my bowels ... time(s) }\end{array}$ & $\begin{array}{l}0,1,2,3,4, \text { more than } 4 \\
\text { times }\end{array}$ \\
\hline $17 a$ & $\begin{array}{l}\text { Since the last beep, I have actually opened my } \\
\text { bowels ... time(s) }\end{array}$ & $\begin{array}{l}0,1,2,3,4, \text { more than } 4 \\
\text { times }\end{array}$ \\
\hline 17al & It looked like this: ... & Bristol Stool Score 1 - 7 \\
\hline 17all & I had to strain & 0 (none) - 10 (very much) \\
\hline 17alll & It feels like my bowels are not completely empty & 0 (none) - 10 (very much) \\
\hline \multicolumn{3}{|c|}{ Mood and psychological factors } \\
\hline 18 & I am feeling good & 0 (none) - 10 (very much) \\
\hline 19 & I am feeling low & 0 (none) - 10 (very much) \\
\hline 20 & I am feeling anxious & 0 (none) - 10 (very much) \\
\hline 21 & I am feeling irritated & 0 (none) - 10 (very much) \\
\hline 22 & I am feeling stressed & 0 (none) - 10 (very much) \\
\hline 23 & I am feeling relaxed & 0 (none) - 10 (very much) \\
\hline 24 & I am worried & 0 (none) - 10 (very much) \\
\hline \multicolumn{3}{|c|}{ Context and environment } \\
\hline 25 & Where am I? & $\begin{array}{l}\text { At home, at someone } \\
\text { else's home, work/school } \\
\text { public place, on my way, } \\
\text { somewhere else }\end{array}$ \\
\hline
\end{tabular}




\begin{tabular}{|c|c|c|}
\hline \multicolumn{3}{|c|}{ Context and environment (continued) } \\
\hline 26 & What am I doing (just before the beep)? & $\begin{array}{l}\text { Resting, work/school work, } \\
\text { household work/shopping, } \\
\text { hygiene/self-care, } \\
\text { eating/drinking, } \\
\text { relaxing/recreation, } \\
\text { sports, travelling, } \\
\text { something else }\end{array}$ \\
\hline 27 & I feel (un)comfortable doing this & $\begin{array}{l}-5 \text { (extremely } \\
\text { uncomfortable) - } \\
5 \text { (extremely comfortable) }\end{array}$ \\
\hline 28 & My symptoms are limiting my current activities & 0 (none) - 10 (very much) \\
\hline 29 & Who is with me? & $\begin{array}{l}\text { Partner/children, friends, } \\
\text { housemates, colleagues, } \\
\text { family (other than those } \\
\text { who live in your house), } \\
\text { acquaintances, } \\
\text { strangers/others, no one }\end{array}$ \\
\hline $29 a$ & I find this company (un)pleasant & $\begin{array}{l}-5 \text { (extremely unpleasant) } \\
-5 \text { (extremely pleasant) }\end{array}$ \\
\hline \multicolumn{3}{|c|}{ Nutrition and drug use } \\
\hline 30 & I have eaten ... since the last beep & $\begin{array}{l}\text { Breakfast, lunch, dinner, a } \\
\text { snack, none of these }\end{array}$ \\
\hline 31 & I ate ... ago & $\begin{array}{l}\text { More than } 15 \text { min., } 15-30 \\
\text { min., } \\
30 \text { min.-1 hour, more than } \\
1 \text { hour }\end{array}$ \\
\hline 32 & Since the last beep I have used ... & $\begin{array}{l}\text { Caffeine (coffee) / theine } \\
\text { (tea), nicotine (smoking), } \\
\text { alcohol, drugs, medication, } \\
\text { none of these }\end{array}$ \\
\hline $32 \mathrm{a}$ & This was following medication: & $\begin{array}{l}\text { Medication for abdominal } \\
\text { pain, other pain relief, } \\
\text { medication for stomach } \\
\text { acidity, medication for } \\
\text { nausea, medication to } \\
\text { stop diarrhea, medication } \\
\text { for constipation, } \\
\text { something else }\end{array}$ \\
\hline
\end{tabular}

Green color indicates items that were newly added to the instrument during phase III: Expert meeting. 